\title{
Parathyroid carcinoma - a study of 29 cases
}

\author{
Grzegorz Józef Kowalski, Adam Bednarczyk, Grzegorz Buła, Agata Gawrychowska, Jacek Gawrychowski \\ Department of General and Endocrine Surgery, Faculty of Medical Sciences in Zabrze, Medical University of Silesia, Katowice, Poland
}

\begin{abstract}
Introduction: Parathyroid carcinoma is a rare condition and accounts for $<1 \%$ of cases of sporadic primary hyperparathyroidism. It accounts for $0.005 \%$ of all cancers. Often the differentiation between adenoma and carcinoma is challenging and requires multidisciplinary cooperation. Complete surgical resection is the treatment of choice.

We present a retrospective analysis of 29 patients who were surgically treated for parathyroid cancer.

Material and methods: Between the years 1983 and 2018, 71 (7.0\%) patients were treated for suspicion of parathyroid cancer among a group of 1019 operated for primary hyperparathyroidism.

Results: We confirmed the diagnosis of parathyroid cancer in $29(2.8 \%)$ patients, 12 men and 17 women, aged 27 to 77 years, mean 55.1 years. That constituted $43.9 \%$ of the 71 patients with initial suspicion of cancer diagnosis. All operated patients were under long-term observation. Conclusions: A diagnosis of parathyroid carcinoma should always be considered during surgery in patients diagnosed with primary hyperparathyroidism, especially in patients with severe hypercalcaemia, significantly enlarged neck circumference, and concomitant diseases of the renal and skeletal system. Parathyroid carcinoma is rarely definitively diagnosed preoperatively or even intraoperatively, and the final diagnosis can be made exclusively after operation. The optimal treatment is a complete surgical resection at a reference centre — specialized in parathyroid surgery — to improve outcomes and provide the best chance of recovery. (Endokrynol Pol 2022; 73 (1): 56-63)

Key words: primary hyperparathyroidism; parathyroid adenoma; parathyroid hyperplasia; parathyroid carcinoma; parathyroidectomy
\end{abstract}

\section{Introduction}

Parathyroid carcinoma was first described by de Quervain in 1904 [1,2] as a non-functioning metastatic carcinoma [2, 3]. Since then, about 1000 cases of the disease have been described [4-6]. Incidence usually accounts for less than $1 \%$ of cases of patients with primary hyperparathyroidism [7]. The prevalence is $0.005 \%$ of all cancers $[3,4,6,8]$. The pathogenesis of parathyroid carcinoma is unknown. It usually has sporadic occurrence and rarely is associated with various kinds of multiple endocrine neoplasia type 1 (MEN1), type 2A (MEN2A), hyperparathyroidism — jaw tumour syndrome (HPT-JT), and familial isolated hyperparathyroidism [3, 8]. The majority of parathyroid carcinoma are hormonally active functional $[1,3,8,9]$. Diagnosis of parathyroid carcinoma is challenging because of the absence of characteristics that allow definite distinction of malignant from benign disease. Surgical resection is the treatment of choice but follow-up approach is often doubtful $[3,9,12]$. The aim of the study was to compare patients treated for parathyroid carcinoma and benign lesions and indicate the related difficulties.

\section{Material and methods}

This is a retrospective study of $71(7.0 \%)$ patients among the group of 1019, operated between the years 1983 and 2019 for primary hyperparathyroidism with suspected parathyroid carcinoma. Ultimately, the diagnosis of parathyroid carcinoma was confirmed in $29(2.8 \%)$ cases. Moreover, this group was compared with the group of $850(83.4 \%)$ cases operated for typical parathyroid adenoma between 1983 and 2019. From the group of 71 operated for primary hyperparathyroidism with suspected parathyroid carcinoma, we identified 29 patients with parathyroid carcinoma - 12 men and 17 women, aged between 27 and 77, mean 55.1 years. Serum level ionized calcium $\left(\mathrm{Ca}^{++}\right)$and PTH levels were measured. We reviewed the clinical presentation of parathyroid carcinoma retrospectively, along with diagnosis, management, and follow-up. Patients were admitted to the clinic as a result of an earlier diagnosis carried out in referring centres. Parathyroid localization studies included ultrasound, sestamibi Tc-99m scintigraphy, SPECT (single photon emission scintigraphy), CT scan, or MRI. The resected lesions were identified and compared to each other in cases of carcinoma suspicion, based on the operation protocols and biochemical as well as histopathological investigation, which contained the number of lesions and histological consistency. The histopathological examination was performed by 2 independent pathologists to confirm the primary diagnosis. After discharge from the clinic, the patients were examined 4 times per year, i.e. every 3 months during first 2 years and later every 6 months for the next 3 years. 
Table 1. Comparison of initial histopathological diagnosis of patients with suspected parathyroid carcinoma to patients with definite diagnosis of parathyroid carcinoma

\begin{tabular}{lcccc}
\hline $\begin{array}{l}\text { Preliminary histopathological } \\
\text { findings }\end{array}$ & $\begin{array}{c}\text { All } \\
(\mathbf{n}=\mathbf{7 1})\end{array}$ & $\begin{array}{c}\text { Carcinoma confirmed } \\
(\mathbf{n}=\mathbf{2 9})\end{array}$ & $\begin{array}{c}\text { Other diagnosis } \\
(\mathbf{n}=\mathbf{4 2})\end{array}$ & $\mathbf{p}$ \\
\hline Hyperplasia & 7 & 2 & 5 & 36 \\
\hline Adenoma & 46 & 10 & 5 & 0.073 \\
\hline Atypical adenoma & 6 & 1 & 0 & 0.071 \\
\hline Carcinoma & 12 & 12 & 0.075 \\
\hline
\end{tabular}

\section{Statistical analysis}

All the collected data were included in a spreadsheet in Microsoft Office Excel 2019. The statistical analysis was performed in Statistica 12.5. After establishing and classification of the data using a Kolmogorow-Smirnow test, we used Student's t-test to compare the data with normal distribution, and for the data of non-normal distribution we used the Mann-Whitney-Wilcoxon U-test. The results are presented as percentage changes, full numbers, means, and standard deviations. The numerical data were compared with those of the Pearson chi-square test. The probability of survival in the studied group of patients was determined using F Cox's test.

\section{Results}

In the group of 71 patients with suspected parathyroid carcinoma , it was finally confirmed in $29(40.8 \%)$ cases (Tab. 1).

There were $17(58.6 \%)$ women and $12(41.4 \%)$ men between 27 and 77 years old, mean 55.1 years. The age of the men treated surgically for parathyroid carcinoma ranged from 27 to 67 , mean 50.1 years, and women from 41 to 77 , mean 54.6 years (Tab. 2). In the study group of patients with parathyroid carcinoma , in $25(86.2 \%)$ patients the tumour was located in the neck. Histopathological examination confirmed the diagnosis of lower left parathyroid carcinoma in 7 (24.1\%) patients, lower right in $16(55.2 \%)$, upper right in $4(13.8 \%)$, upper left in $2(6.9 \%)$ patients, and in $4(13.8 \%)$ patients ectopic located parathyroid carcinoma in the upper mediastinum. The dimensions of the tumour varied from 15 to $65 \mathrm{~mm}$, mean $24.8 \mathrm{~mm}$. No history of irradiation to the neck or familial hyperparathyroidism was reported.

Severe hypercalcaemia was present in $13(44.8 \%)$ patients and palpable lesion in $19(65.5 \%)$. Fifteen $(51.7 \%)$ patients had neck circumference, $18(62.1 \%)$ had difficulty swallowing, and $13(44.8 \%)$ patients had

Table 2. Characteristics of patients treated surgically for primary hyperparathyroidism

\begin{tabular}{|c|c|c|c|c|}
\hline \multirow[b]{2}{*}{ Factor } & \multicolumn{3}{|c|}{ Tumour/No. of patients } & \multirow[b]{2}{*}{$\mathbf{p}$} \\
\hline & $\begin{array}{l}\text { Parathyroid carcinoma } \\
\qquad(n=29)\end{array}$ & $\begin{array}{l}\text { Suspected carcinoma } \\
\qquad(\mathrm{n}=42)\end{array}$ & $\begin{array}{l}\text { Parathyroid adenoma } \\
\qquad(\mathrm{n}=850)\end{array}$ & \\
\hline \multicolumn{5}{|l|}{ Sex } \\
\hline M & 12 & 14 & 156 & \multirow{2}{*}{0.64} \\
\hline $\mathrm{F}$ & 17 & 28 & 694 & \\
\hline \multicolumn{5}{|c|}{ Age (years) } \\
\hline \multirow{2}{*}{ M } & 27-67 & 21-69 & 21-79 & \multirow{2}{*}{0.87} \\
\hline & (mean 50.1) & (mean 55.0) & (mean 55.9) & \\
\hline \multirow{2}{*}{$\mathrm{F}$} & $41-77$ & $19-71$ & $19-80$ & \multirow{2}{*}{0.45} \\
\hline & (mean 54.6) & (mean 55.4) & (mean 56.2) & \\
\hline \multicolumn{5}{|c|}{ Symptoms } \\
\hline Yes & 27 & 38 & 702 & \multirow{2}{*}{0.64} \\
\hline No & 2 & 4 & 148 & \\
\hline \multicolumn{5}{|c|}{ Localization } \\
\hline \multirow{2}{*}{ Left } & Superior & 3 & 75 & \multirow{2}{*}{0.45} \\
\hline & Inferior & 11 & 236 & \\
\hline \multirow{2}{*}{ Right } & Superior & 5 & 106 & \multirow{2}{*}{0.52} \\
\hline & Inferior & 23 & 433 & \\
\hline
\end{tabular}


Table 3. Diagnostics of patients with parathyroid carcinoma, suspected carcinoma, and parathyroid adenoma

\begin{tabular}{|c|c|c|c|c|}
\hline \multirow[b]{2}{*}{ Feature } & \multicolumn{3}{|c|}{ Tumour/No. of patients } & \multirow[b]{2}{*}{$\mathbf{p}$} \\
\hline & $\begin{array}{l}\text { Parathyroid carcinoma } \\
\qquad(\mathrm{n}=29)\end{array}$ & $\begin{array}{l}\text { Suspected carcinoma } \\
\qquad(\mathrm{n}=42)\end{array}$ & $\begin{array}{l}\text { Parathyroid adenoma } \\
\qquad(\mathrm{n}=850)\end{array}$ & \\
\hline Clinically (\%) & $19(65.5 \%)$ & $21(50.0 \%)$ & $34(4.0 \%)$ & 0.037 \\
\hline Difficulty swallowing (\%) & $18(62.1 \%)$ & $8(19.0 \%)$ & $34(4.0 \%)$ & 0.018 \\
\hline Hoarseness (\%) & $13(44.8 \%)$ & $19(45.2 \%)$ & $68(16.0 \%)$ & 0.029 \\
\hline Palpably (\%) & $19(95.5 \%)$ & $8(19.0 \%)$ & $34(4.0 \%)$ & 0.019 \\
\hline $\begin{array}{l}\text { Widening of the neck } \\
\text { Circumference (\%) }\end{array}$ & $15(51.7 \%)$ & $20(47.6 \%)$ & $85(20.0 \%)$ & 0.036 \\
\hline Imaging studies (\%) & $28(96.6 \%)$ & $37(88.1 \%)$ & $85(20.0 \%)$ & 0.205 \\
\hline Histopathologically (\%) & $28(96.6 \%)$ & 5 (11.9\%) & 0 & 0.056 \\
\hline
\end{tabular}

*The group of 850 consecutive patients with benign parathyroid adenoma treated for primary hyperparathyroidism

hoarseness. In the group of patients with parathyroid carcinoma $27(93.1 \%)$ were symptomatic while 2 $(6.9 \%)$ patients were asymptomatic or did not notice any symptoms (Tab. 3). Patients with parathyroid carcinoma were characterized by higher frequency of depression - $13(44.8 \%)$, musculoskeletal symptoms myalgia and bone pain - $25(86.2 \%)$, pathological bone fractures - 4 $(13.7 \%)$, nephrolithiasis - $21(72.4 \%)$, osteoporosis - $20(69.0 \%)$, and stomach/duodenal ulcers $-4(13.8 \%)$.

The mean level of ionized calcium concentration $\left(\mathrm{Ca}^{++}\right)$in the serum in patients before surgery was $2.03 \mathrm{mmol} / \mathrm{L}$, while PTH was mean 313.4 pg/mL. Immediately after surgery, the level of ionized calcium in the serum decreased and amounted to the mean of $1.1 \mathrm{mmol} / \mathrm{L}$, and PTH to the mean of $39.62 \mathrm{pg} / \mathrm{mL}$. Significantly higher levels of PTH concentration were detected in patients operated for parathyroid carcinoma compared to patients treated for primary hyperparathyroidism due to benign parathyroid adenoma in all studies, i.e. before surgery $(p=0.012)$, immediately after surgery (up to 30 days) ( $p<0.001$ ), and in the late follow-up period $(\mathrm{p}<0.001)$. In all studies, both before surgery $(p<0.001)$, immediately after $(p=0.046)$, and in the late follow-up period ( $p<0.001)$, significantly higher creatinine levels were found in patients treated for parathyroid carcinoma compared to patients treated for benign changes. Similarly, in patients with parathyroid carcinoma , significantly higher levels of urea concentration were found both before surgery $(p=0.022)$ and in later control tests $(\mathrm{p}=0.015)$ compared to patients operated on for parathyroid adenoma. In patients operated on for parathyroid carcinoma, late follow-up examinations also showed a significantly higher level of $\mathrm{K}^{+}$concentration in the blood $(\mathrm{p}=0.025)$ and the level of inorganic phosphorus $(p=0.036)$, compared to patients treated for primary hyperparathyroidism of a different background (Tab. 4).
Among 29 patients operated for parathyroid carcinoma, $9(31.0 \%)$ patients underwent en bloc resection and $8(27.6 \%)$ had parathyroidectomy with the removal of the ipsilateral thyroid lobe. The other 12 (41.4\%) patients had tumour resection only. Nine of the treated patients underwent a second operation - en bloc resection. Five of the 9 patients who had en bloc resection at the initial operation had recurrences and was revision of the neck and upper mediastinum. One of them died because of hypercalcaemia after a reoperation. Among the $14(48.3 \%)$ patients who were re-operated for hypercalcemia, 3 died 7, 8, and 14 years after the first operation. From this group, $2(6.9 \%)$ patients suffered from persistent hypercalcaemia, $9(31.0 \%)$ patients experienced recurrence by the time of data collection, and in $3(10.3 \%)$ there was no change in calcium level. In control tests, the concentration of ionized calcium in the serum ranged from 1.07 to 2.24 , mean $1.25 \mathrm{mmol} / \mathrm{L}$. Similarly, a reduction in the level of PTH concentration was found, ranging from 12 to 272 , mean $78.57 \mathrm{pg} / \mathrm{mL}$. The median disease-free interval was 18 months, and the median survival was 117 months. Fifteen $(51.7 \%$ ) patients were alive with no evidence of disease (Tab. 4).

Postoperative patient monitoring showed that in most of the cases the implemented surgical treatment was successful. Fifteen (51.7\%) patients did not have symptoms after treatment, their calcium and parathyroid hormone levels stabilized, and they did not experience further episodes of hypercalcaemia. Six (20.7\%) patients had metastatic disease, most commonly to the neck and spine. One $(3.4 \%)$ patient had femoral metastasis, 4 (13.8\%) patients developed postoperative hungry bone syndrome, $14(48.3 \%)$ patients had more than one neck surgery, $3(10.3 \%)$ patients received adjuvant radiation, and $5(17.2 \%)$ patients had a history of other malignancies, including lung cancer, breast, and colon cancer. MEN1 was diagnosed in 1 patient. Four (13.8\%) patients died as a result of the further progression of the 
Table 4. Presentation of laboratory test results of patients diagnosed with parathyroid carcinoma and parathyroid adenoma

\begin{tabular}{|c|c|c|c|c|c|c|}
\hline \multirow[t]{2}{*}{ Laboratory tests } & \multirow[t]{2}{*}{ Time vs. surgery } & \multicolumn{2}{|c|}{$\begin{array}{l}\text { Parathyroid adenoma } \\
\qquad(\mathrm{n}=850)\end{array}$} & \multicolumn{2}{|c|}{$\begin{array}{l}\text { Parathyroid carcinoma } \\
\qquad(\mathrm{n}=29)\end{array}$} & \multirow[t]{2}{*}{$\mathbf{p}$} \\
\hline & & Mean & \pm SD & Mean & $\pm S D$ & \\
\hline \multirow{3}{*}{ PTH } & Before & 164.26 & 137.73 & 313.40 & 381.08 & 0.012 \\
\hline & up to 30 days & 20.90 & 14.14 & 39.62 & 28.08 & 0.000 \\
\hline & after 5 years & 22.92 & 9.62 & 78.57 & 103.11 & 0.000 \\
\hline \multirow{3}{*}{ Ionized calcium $\left(\mathrm{Ca}^{++}\right)$} & Before & 1.80 & 0.22 & 2.03 & 0.39 & 0.027 \\
\hline & up to 30 days & 1.10 & 0.11 & 1.10 & 0.14 & NS \\
\hline & after 5 years & 1.24 & 0.10 & 1.25 & 0.11 & NS \\
\hline \multirow{3}{*}{ Urea } & Before & 5.43 & 2.44 & 6.77 & 3.15 & 0.022 \\
\hline & up to 30 days & 5.56 & 2.53 & 6.34 & 3.55 & NS \\
\hline & after 5 years & 5.17 & 1.50 & 11.48 & 21.90 & 0.015 \\
\hline \multirow{3}{*}{ Creatinine } & Before & 64.23 & 22.67 & 92.45 & 40.77 & 0.000 \\
\hline & up to 30 days & 68.60 & 57.62 & 95.64 & 56.36 & 0.046 \\
\hline & after 5 years & 62.63 & 18.66 & 100.65 & 62.62 & 0.000 \\
\hline \multirow{3}{*}{ Inorganic phosphorus } & Before & 0.98 & 0.23 & 1.08 & 0.31 & NS \\
\hline & up to 30 days & 1.29 & 4.41 & 1.04 & 0.24 & NS \\
\hline & after 5 years & 1.18 & 0.10 & 1.16 & 0.52 & 0.036 \\
\hline
\end{tabular}

SD — standard deviation; PTH — parathyroid hormone; NS — non-significant

cancer $-4,7,8$, and 14 years after the first operation. Death was caused by uncontrollable hypercalcaemia supported by widespread metastasis to the bones and lungs. The mean time of recurrence after diagnosis was 2.9 years, and the mean survival was 8.3 years for the patients who have died. Five patients were lost to follow-up. Such a comparison gives information that survival rate in patients with cancer oscillate between 0.8 and 0.95 during the first 10 years, decreasing to a value of $>0.6$ during the next 15 years (Fig. 1).

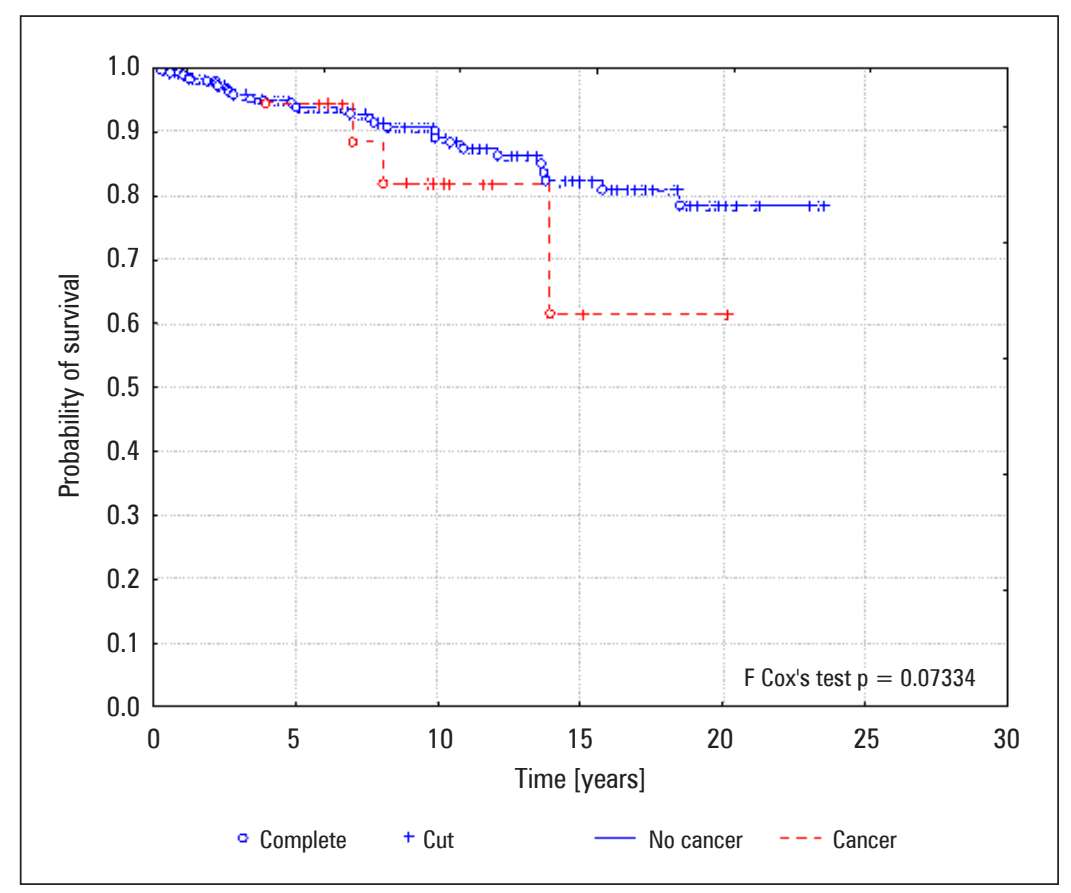

Figure 1. The probability of survival in the group of 42 patients with suspected parathyroid cancer compared to 29 patients with definite diagnosis of parathyroid cancer 


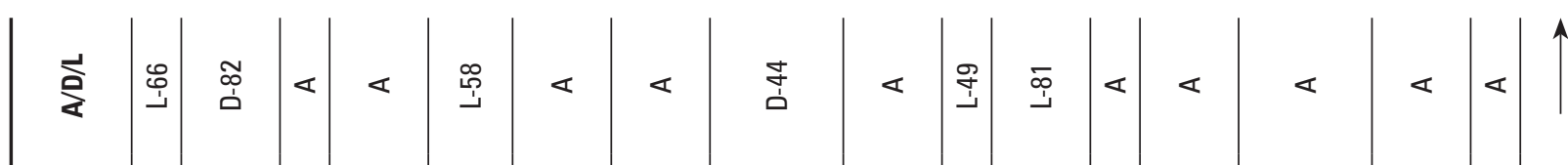

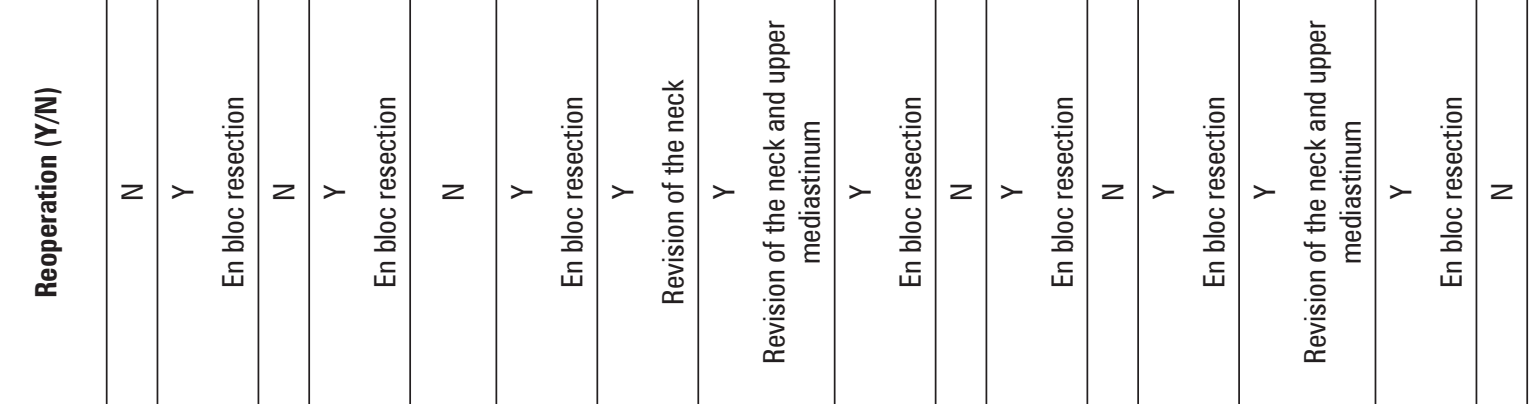

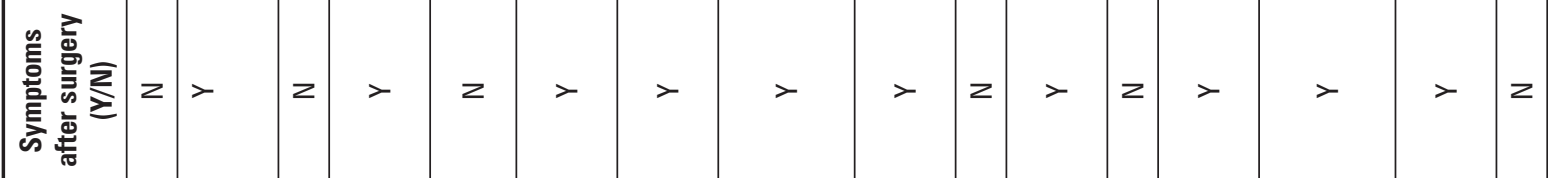

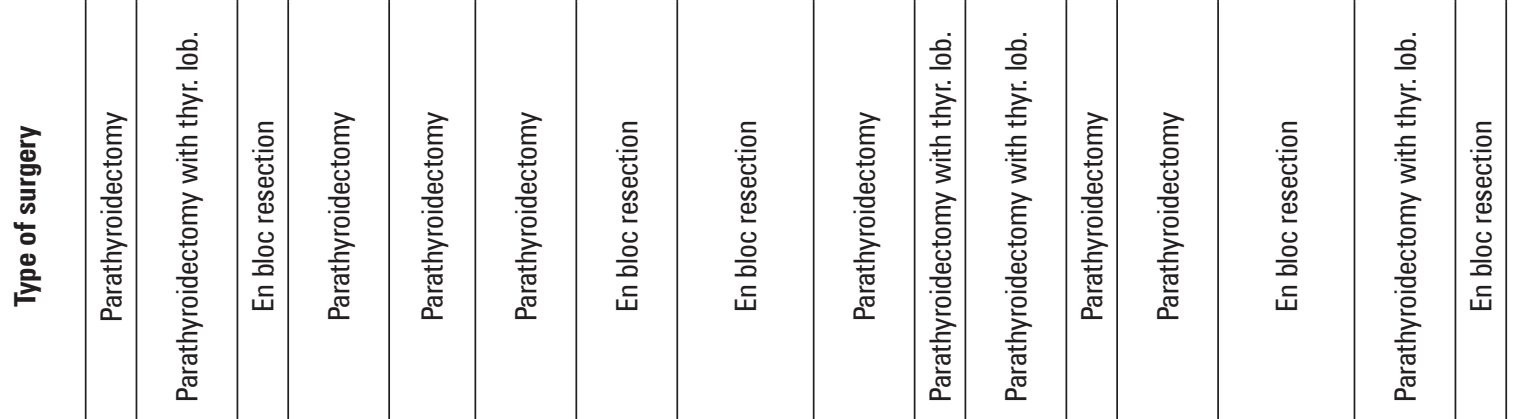

$$
\begin{aligned}
& \text { 胥 }
\end{aligned}
$$

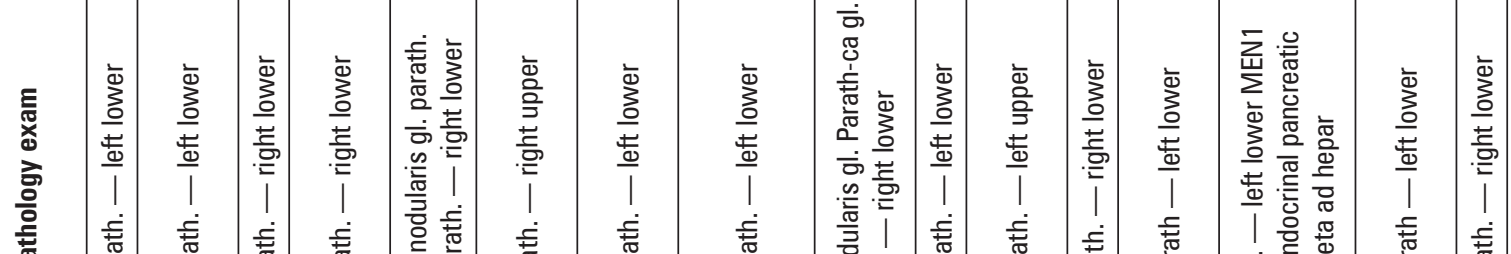

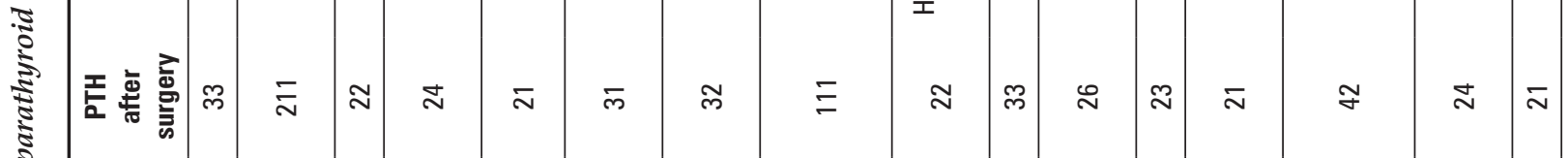

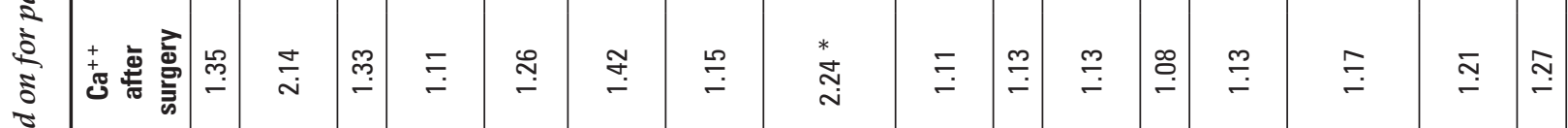

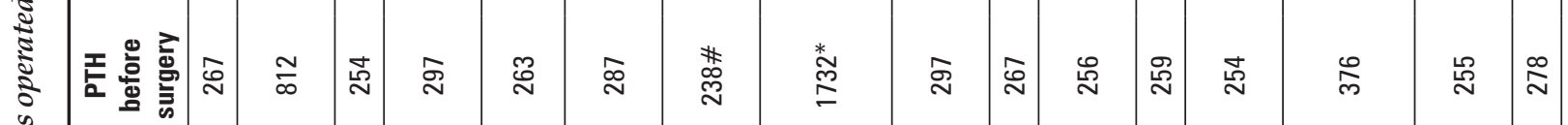

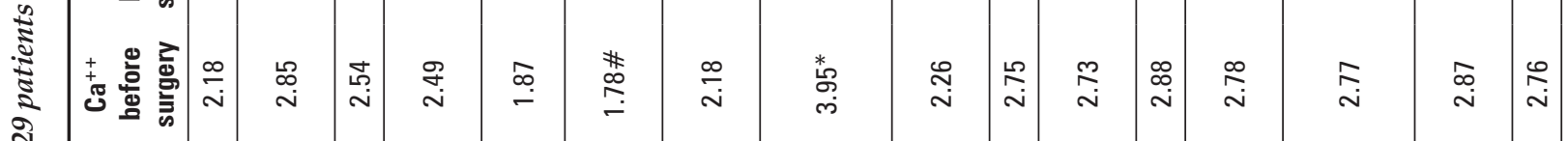

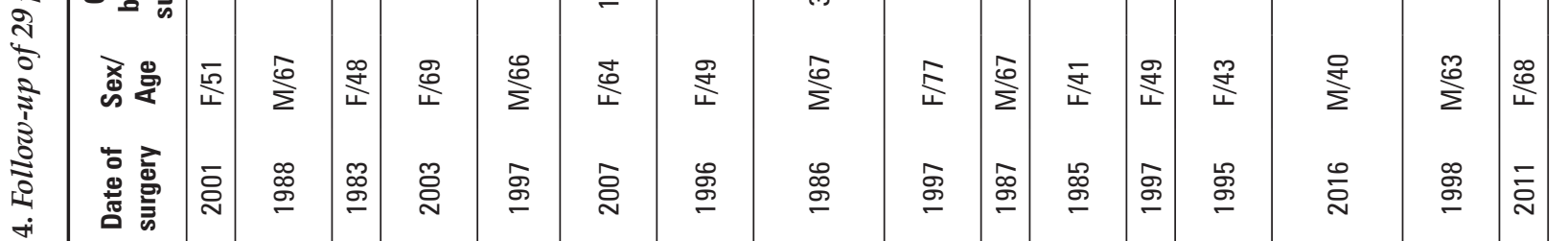

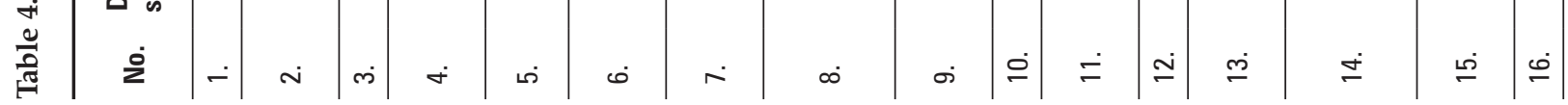




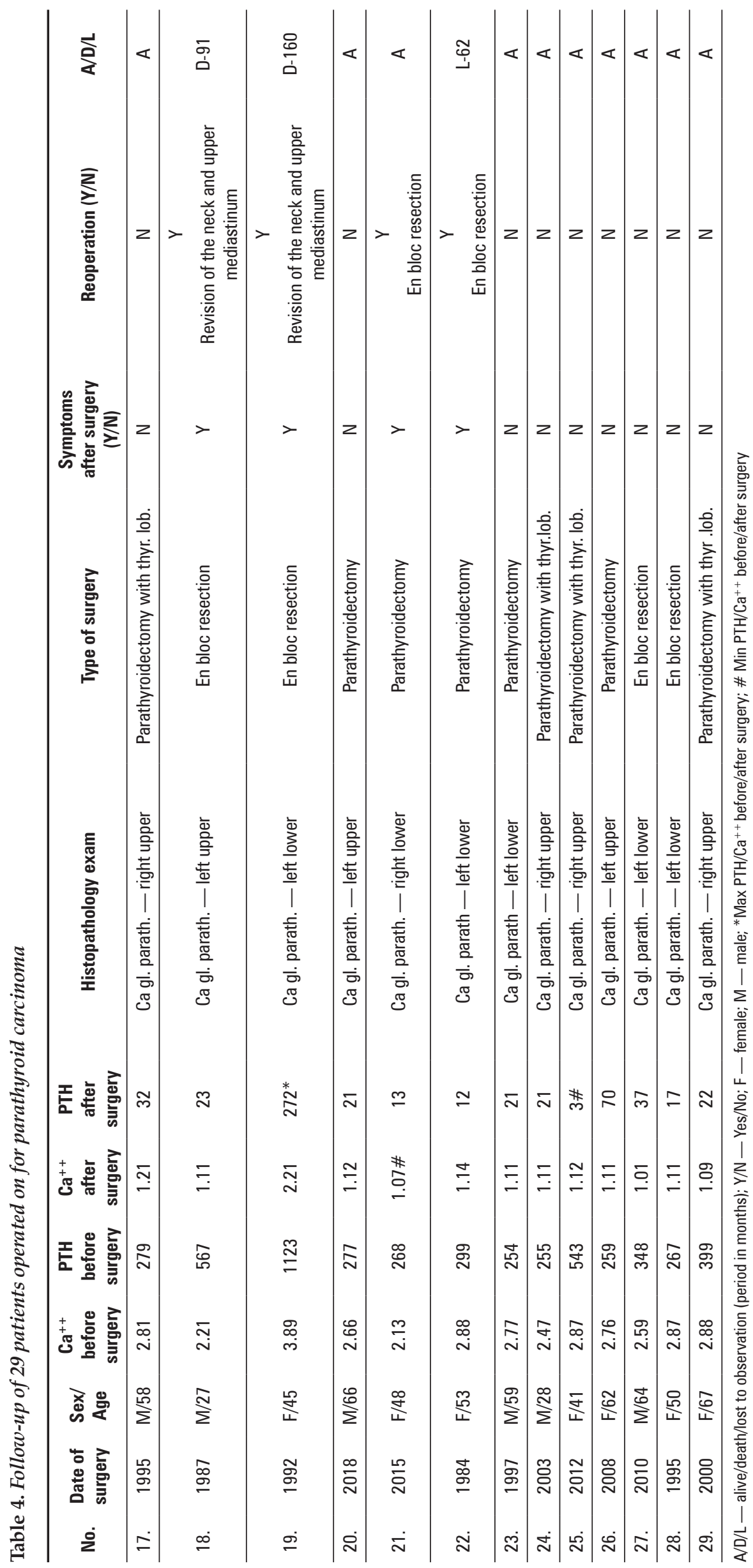




\section{Discussion}

The aetiology of parathyroid carcinoma is unclear. Most of these cancers are sporadic, but the association with familial hyperparathyroidism syndromes including multiple endocrine neoplasia (MEN) types 1 and $2 \mathrm{~A}$ and jaw tumour syndrome hyperparathyroidism suggests a possible genetic predisposition $[1,2,18]$. The most frequent genetic anomalies associated with parathyroid cancer are inactive somatic mutations of the parafibromin gene (CDC73/HRPT2) [3, 4, 16]. The greatest challenge to the clinician is to distinguish parathyroid carcinoma from the far more common entities of parathyroid adenoma, atypical adenoma, or hyperplasia [3, $5,12]$. Patients diagnosed with parathyroid carcinoma are most often characterized by the presence of a mass on the neck, often exhibiting symptoms and complications of severe primary hyperparathyroidism, such as: skeletal involvement including osteopaenia, osteoporosis, osteofibrosis, osteitis fibrosa cystica, subperiosteal resorption, pathologic fractures, bone pain, and severe depression [3, 6, 8, 21]. Renal disease manifests mostly as nephrolithiasis and renal insufficiency, with a reported prevalence of 56 and $84 \%$, respectively $[3,7,15]$. Clinically, the physician should consider diagnosis of carcinoma when the patient presents renal and bone symptoms simultaneously, because dual presentation is quite rare in cases of adenomas. A highly alarming clinical sign is hoarseness due to retrograde laryngeal nerve palsy $[3,10,13]$. Some patients may present with hypercalcaemic crisis $[3,9]$. Only $2 \%$ of parathyroid cancers are asymptomatic [11]. A highly relevant factor is in-depth and repeated diagnostics [3, 12,34]. On physical examination and sonographic evaluation, masses bigger than $3 \mathrm{~cm}$ should be considered malignant [7]. Tc (99 m)-sestamibi scintigraphy can help with the diagnosis by localization of changed parathyroid gland, with a sensitivity from 70 to $90 \%[9,10,14]$. Unfortunately, recent studies have shown that even this method is not very accurate and many patients cannot be diagnosed only upon the results $[2,11,18]$. Our paper confirmed this observation. Both CT and MRI may provide information about lesion extension, eventual invasion into surrounding structures, lymph nodes or distant metastasis [3, 5, 26, 29]. CT usually shows low sensitivity in detecting parathyroid carcinoma $[6,16$, 26], while MRI is adequate for soft tissue studies [14, 23, 25]; nevertheless, the surgeon decides about the scope of operation based on the intraoperative image. Few studies are available on the use of ${ }^{18} \mathrm{~F}$-fluorodeoxyglucose positon emission tomography integrated with computed tomography $\left(\left[{ }^{18} \mathrm{~F}\right] \mathrm{FDG}\right.$ PET/CT $)$, aimed at the early identification of metastases/recurrence [3, 17-19]. Histopathological studies and genetic analysis of lesions can help with the diagnosis of cancerous lesions, but they are not always definitive $[3,12,15,30]$. The diagnosis of parathyroid carcinoma is confirmed if there is an obvious sign of invasive growth of the tumour, either invasion of capsule, vessels, neighbouring structure, or the presence of metastasis at the time of presentation. However, metastatic progression of the tumour is very slow, and usually the cancer is not in an earlier stage $[5,28,31,32]$. The therapeutic outcome for this patient group of parathyroid cancer was very satisfactory with a high rate of curability. On the other hand, patients with cancer are at higher risk of recurrence of symptoms of hyperparathyroidism; thus, it is very important from a surgical point of view to resect en bloc all of the tumour along with the surrounding tissues to prevent relapse of the malignancy [3, $19,33]$. We think that if the diagnosis is confirmed or highly suspected during primary operation, then the inspection of all 4 parathyroid glands should be done. Additionally, adjacent lymph nodes should be checked $[3,18,21,35]$. If the diagnosis is confirmed based on the result of pathological studies of tumour resected during primary surgery, the treatment becomes more complex $[20-22,24]$. Reoperation is advised in cases in which the surgery failed to restore levels of calcium and PTH. In cases where, after the primary surgery, the symptoms resolved, patients should be strictly monitored and the levels of ionized calcium and PTH should be measured regularly for surveillance of cancer return [7, 19, 25, 28]. Recurrence of parathyroid cancer within 1-2 years of initial appropriate surgery is a feature of aggressive biological behaviour, and it may occur despite initial en block resection, and it is associated with a shorter survival. Unfortunately, parathyroid cancers in $50 \%$ of cases reoccur usually $2-3$ years after primary operation, but longer periods were also observed [19, 24, 37]. A lymphadenectomy may therefore not be justified if no enlarged nodes are present. Distant metastases to the lung or bone are rarely the first presentation of parathyroid cancer but are frequent. Lymph node metastases from parathyroid are the cause of persistent hypercalcaemia after surgery [19, 27, 37]. Prognosis is variable and the most important factor is quick diagnosis and resection of a whole tumour during initial treatment. The National Surveillance, Epidemiology, and End Results database, recently reported a 10 -year survival of $67.8 \%$ [32]. In our material, considering the confirmed deaths and patients with whom we lost contact, it was $69.0 \%$. New therapies, including immunotherapy and the calcimimetics, are successfully used in some patients with metastatic parathyroid carcinoma. Immunotherapy achieves hormonal and biochemical normalization by immunizing against PTH in patients with parathyroid cancer. Calcimimetics are a class of drugs with agonist 
action at the calcium-sensing receptor for the control of symptoms of severe free interval cancer [26, 29, 34].

\section{Conclusions}

A diagnosis of parathyroid carcinoma should always be considered during surgery in patients diagnosed with primary hyperparathyroidism, especially in patients with severe hypercalcaemia, significantly enlarged neck circumference, and concomitant diseases of the renal and skeletal system.

Parathyroid carcinoma is rarely definitively diagnosed preoperatively or even intraoperatively, and the final diagnosis can be made exclusively after operation.

The optimal treatment is a complete surgical resection at a reference centre - specialized in parathyroid surgery - to improve outcomes and provide the best chance of recovery.

\section{References}

1. Wieneke JA, Smith A. Parathyroid adenoma. Head Neck Pathol. 2008; 2(4): 305-308, doi: 10.1007/s12105-008-0088-8, indexed in Pubmed: 20614300.

2. Baj J, Sitarz R, Łokaj M, et al. Preoperative and Intraoperative Methods of Parathyroid Gland Localization and the Diagnosis of Parathyroid Adenomas. Molecules. 2020; 25(7), doi: 10.3390/molecules25071724, indexed in Pubmed: 32283730.

3. Kowalski G, Bula G, Polczyk J, et al. Benign Parathyroid Gland Tumors and their Heterogeneity. J Surg Res. 2020; 03(04), doi: 10.26502/jsr.10020102.

4. Ramaswamy AS, Vijitha T, Kumarguru BN, et al. Atypical parathyroid adenoma. Indian J Pathol Microbiol. 2017; 60(1): 99-101, doi: 10.4103/0377-4929.200055, indexed in Pubmed: 28195102.

5. Ferraro V, Sgaramella LI, Di Meo G, et al. Current concepts in parathyroid carcinoma: a single Centre experience. BMC Endocr Disord. 2019; 19(Suppl 1): 46, doi: 10.1186/s12902-019-0368-1, indexed in Pubmed: 31142320.

6. Cetani F, Pardi E, Marcocci C, et al. Should parafibromin staining replace HRTP2 gene analysis as an additional tool for histologic diagnosis of parathyroid carcinoma? Eur J Endocrinol. 2007; 156(5): 547-554 doi: 10.1530/EJE-06-0720, indexed in Pubmed: 17468190.

7. Cetani F, Pardi E, Marcocci C, et al. Should parafibromin staining replace HRTP2 gene analysis as an additional tool for histologic diagnosis of parathyroid carcinoma? Eur J Endocrinol. 2007; 156(5): 547-554, doi: 10.1530/EJE-06-0720, indexed in Pubmed: 17468190.

8. Lo CY, Lang BH, Chan WF, et al. A prospective evaluation of preoperative localization by technetium-99m sestamibi scintigraphy and ultrasonography in primary hyperparathyroidism. Am J Surg. 2007; 193(2): 155-159 doi: 10.1016/j.amjsurg.2006.04.020, indexed in Pubmed: 17236840.

9. Gawrychowski J, Kowalski GJ, Buła G, et al. Surgical Management of Primary Hyperparathyroidism-Clinicopathologic Study of 1019 Cases from a Single Institution. J Clin Med. 2020; 9(11), doi: 10.3390/jcm9113540, indexed in Pubmed: 33147842

10. Sharretts JM, Kebebew E, Simonds WF. Parathyroid cancer. Semin Oncol. 2010; 37(6): 580-590, doi: 10.1053/j.seminoncol.2010.10.013, indexed in Pubmed: 21167377.

11. Givi B, Shah JP. Parathyroid carcinoma. Clin Oncol (R Coll Radiol). 2010; 22(6): 498-507, doi: 10.1016/j.clon.2010.04.007, indexed in Pubmed: 20510594.

12. Al-Kurd A, Mekel M, Mazeh H. Parathyroid carcinoma. Surg Oncol. 2014; 23(2): 107-114, doi: 10.1016/j.suronc.2014.03.005, indexed in Pubmed: 24742584.

13. Thompson L. Benign neoplasms of the parathyroid gland. Head Neck Pathol. 2013: 644-652, doi: 10.1016/b978-1-4377-2607-7.00035-x.

14. Salcuni AS, Cetani F, Guarnieri V, et al. Parathyroid carcinoma. Bes Pract Res Clin Endocrinol Metab. 2018; 32(6): 877-889, doi: 10.1016/j. beem.2018.11.002, indexed in Pubmed: 30551989.
15. Hong N, Yoon HJ, Lee YH, et al. Serum PTHrP Predicts Weight Loss in Cancer Patients Independent of Hypercalcemia, Inflammation, and Tumor Burden. J Clin Endocrinol Metab. 2016; 101(3): 1207-1214, doi: 10.1210/jc.2015-3785, indexed in Pubmed: 26765580.

16. Baser H. Differential Diagnosis of Atypical Parathyroid Adenoma and Parathyroid Carcinoma in a Case With Severe Hypercalcemia. J Med Case. 2013, doi: 10.4021/jmc1198w.

17. McCoy KL, Seethala RR, Armstrong MJ, et al. The clinical importance of parathyroid atypia: is long-term surveillance necessary? Surgery. 2015; 158(4): 929-35; discussion 935, doi: 10.1016/j.surg.2015.06.022, indexed in Pubmed: 26210223

18. Shane E. Clinical review 122: Parathyroid carcinoma. J Clin Endocrino Metab. 2001; 86(2): 485-493, doi: 10.1210/jcem.86.2.7207, indexed in Pubmed: 11157996.

19. Kebebew E. Parathyroid carcinoma, a rare but important disorder for endocrinologists, primary care physicians, and endocrine surgeons. Thyroid. 2008; 18(4): 385-386, doi: 10.1089/thy.2008.0051, indexed in Pubmed: 18348705

20. Cetani F, Pardi E, Marcocci C. Update on parathyroid carcinoma. J Endocrinol Invest. 2016; 39(6): 595-606, doi: 10.1007/s40618-016-0447-3, indexed in Pubmed: 27001435.

21. Kassahun WT, Jonas S. Focus on parathyroid carcinoma. Int J Surg. 2011 9(1):13-19, doi: 10.1016/j.ijsu. 2010.09.003, indexed in Pubmed: 20887820

22. Kamycheva E, Sundsfjord J, Jorde R. Serum parathyroid hormone level is associated with body mass index. The 5th Tromsø study. Eur J Endocrinol. 2004; 151(2): 167-172, doi: 10.1530/eje.0.1510167, indexed in Pubmed: 15296470.

23. Bolland MJ, Grey AB, Gamble GD, et al. Association between primary hyperparathyroidism and increased body weight: a meta-analysis. J Clin Endocrinol Metab. 2005; 90(3): 1525-1530, doi: 10.1210/jc.2004-1891, indexed in Pubmed: 15613408 .

24. Adam MA, Untch BR, Danko ME, et al. Severe obesity is associated with symptomatic presentation, higher parathyroid hormone levels, and increased gland weight in primary hyperparathyroidism. J Clin Endocrinol Metab. 2010; 95(11): 4917-4924, doi: 10.1210/jc.2010-0666, indexed in Pubmed: 20685860.

25. Wynne AG, van Heerden J, Carney JA, et al. Parathyroid carcinoma: clinical and pathologic features in 43 patients. Medicine (Baltimore). 1992; 71(4): 197-205, indexed in Pubmed: 1518393.

26. Rodrigo JP, Hernandez-Prera JC, Randolph GW, et al. Parathyroid cancer: An update. Cancer Treat Rev. 2020; 86: 102012, doi: 10.1016/j. ctrv.2020.102012, indexed in Pubmed: 32247225

27. Wei $\mathrm{CH}$, Harari A. Parathyroid carcinoma: update and guidelines for management. Curr Treat Options Oncol. 2012; 13(1): 11-23, doi: 10.1007/s11864-011-0171-3, indexed in Pubmed: 22327883.

28. Pelizzo MR, Piotto A, Bergamasco A, et al. [Parathyroid carcinoma. Therapeutic strategies derived from 20 years of experience]. Minerva Endocrinol. 2001; 26(1): 23-29, indexed in Pubmed: 11323564.

29. Apaydin T, Yavuz DG. Seven cases of parathyroid carcinoma and review of the literature. Hormones (Athens). 2021; 20(1): 189-195, doi: 10.1007/s42000-020-00220-y, indexed in Pubmed: 32578053

30. Yamamoto T. Comment on "Clinical Review 122: Parathyroid Carcinoma". J Clin Endocrinol Metab. 2001; 86(10): 5091-5091, doi: $10.1210 /$ jc.86.10.5091.

31. Rawat N, Khetan N, Williams DW, et al. Parathyroid carcinoma Br J Surg. 2005; 92(11): 1345-1353, doi: 10.1002/bjs.5182, indexed in Pubmed: 16237743.

32. Lee PK, Jarosek SL, Virnig BA, et al. Trends in the incidence and treatment of parathyroid cancer in the United States. Cancer. 2007; 109(9): 1736-1741, doi: 10.1002/cncr.22599, indexed in Pubmed: 17372919.

33. Ippolito G, Palazzo FF, Sebag F, et al. Intraoperative diagnosis and treatment of parathyroid cancer and atypical parathyroid adenoma. Br J Surg. 2007; 94(5): 566-570, doi: 10.1002/bjs.5570, indexed in Pubmed: 17380564

34. Kowalski GJ, Buła G, Żądło D, et al. Primary hyperparathyroidism. Endokrynol Pol. 2020; 71(3): 260-270, doi: 10.5603/EP.a2020.0028, indexed in Pubmed: 32797471.

35. Kutahyalioglu M, Nguyen HaT, Kwatampora L, et al. Genetic profiling as a clinical tool in advanced parathyroid carcinoma. J Cancer Res Clin Oncol. 2019; 145(8): 1977-1986, doi: 10.1007/s00432-019-02945-9, indexed in Pubmed: 31309300

36. Zhu R, Wang Z, Hu Ya. Prognostic role of parafibromin staining and CDC73 mutation in patients with parathyroid carcinoma: A systematic review and meta-analysis based on individual patient data. Clin Endocrinol (Oxf). 2020; 92(4): 295-302, doi: 10.1111/cen.14161, indexed in Pubmed: 31945198.

37. Madkhali T, Alhefdhi A, Chen $\mathrm{H}$, et al. Primary hyperparathyroidism Ulus Cerrahi Derg. 2016; 32(1): 58-66, doi: 10.5152/UCD.2015.3032, indexed in Pubmed: 26985167. 